\title{
A qualitative study to define meaningful change in physical function after weight-loss.
}

\section{Jiat Ling Poon}

Eli Lilly and Company

\section{Chris Marshall}

DRG Abacus: DRG Bicester

\section{Chloe Johnson}

DRG Abacus: DRG Bicester

Hannah Pegram ( $\sim$ hannah.pegram@clarivate.com )

DRG Abacus: DRG Bicester https://orcid.org/0000-0002-4446-4531

\section{Maile Hunter}

IQVIA

Hongjun Kan

Eli Lilly and Company

Nadia Ahmad

Eli Lilly and Company

\section{Research Article}

Keywords: Adults, Obesity, Physical activity, Quality of life

Posted Date: May 3rd, 2021

DOl: https://doi.org/10.21203/rs.3.rs-384039/v1

License: (a) (i) This work is licensed under a Creative Commons Attribution 4.0 International License.

Read Full License 


\section{Abstract}

Purpose This study explored perceptions of meaningful weight-loss and the level of change on two patient-reported outcome (PRO) measures, the 36-item Short Form Health Survey ${ }^{\circledR}$ [SF-36v2 $\left.{ }^{\circledR}\right]$ and Impact of Weight on Quality of Life Lite-Clinical Trials @ [IWQOL-Lite-CT @ ], that individuals living with overweight or obesity consider to be meaningful and indicative of treatment success. Methods Thirtythree qualitative interviews were conducted in the US with adults living with overweight or obesity. Concept elicitation explored perceptions of minimally important/meaningful weight-loss using openended questions. Cognitive debriefing was used to understand thresholds for meaningful change on both measures. Results Most participants ( $n=23 / 33$ ) expected a $5 \%$ total body weight-loss to yield some benefit in physical functioning, while all participants expected a $10 \%$ weight-loss to provide a meaningful and noticeable improvement in their physical functioning. Participants indicated that an item-level 1-point score change on each measure would represent a noticeable improvement in physical functioning and indicate treatment success. Conclusions Participants expected moderate weight losses to be noticeable, with $\geq 10 \%$ weight-loss yielding the most consistent results. The findings suggested that both measures provide strong opportunity to demonstrate treatment benefit in relation to physical functioning as a small change on the response scale would represent a noticeable improvement in participants' daily lives.

\section{Background}

Nearly a third of the world's population is now classified as living with overweight or obesity [1,2] with worldwide prevalence tripling between 1974 and 2016 [3]. Obesity is a chronic disease associated with serious metabolic, psychological and physical sequelae, including type 2 diabetes (T2DM), cardiovascular disease, depression, sleep apnea, osteoarthritis, increased risk of cancer and more recently, Covid-19 [4-6]. Compounding these effects, obesity causes a significant reduction in healthrelated quality of life (HRQoL), including physical functioning [7, 8], ability to carry out normal activities of daily living (ADLs) $[9,10]$, emotional functioning [8] and bodily pain [11].

As HRQoL, including physical functioning, is an important concern for individuals living with obesity, it has been recommended that HRQoL be assessed as part of weight management treatment and research [12]. Patient-reported outcome (PRO) measures are increasingly being used in clinical trials to evaluate HRQoL. Two PRO measures have been frequently used in prior weight-management studies: the acute 36item Short Form Health Survey $\AA$ (SF-36®) [13-15] and versions of the Impact of Weight on Quality of Life (IWQOL) measure, including the Lite-Clinical Trials Version@ (IWQOL-Lite-CT@) [16, 17].

The SF-36 is a PRO measure that assesses eight domains of HRQoL, including Physical Function, and provides two health component summary scores [13]. The physical function domain is comprised of 10items assessing activities completed during a typical day and how a participant's health now limits them in these activities, assessed on a three-point Likert severity scale. 
The IWQOL-Lite-CT version was designed for use in the context of clinical trials for adults living with overweight/obesity, both with and without T2DM, with the potential to support labeling claims for treatments of chronic weight management. It consists of 20-items across two domains (physical and psychosocial); scores for a physical function composite, comprising of a subset of items in the physical domain can also be obtained $[16,17]$.

Studies of lifestyle-based interventions and pharmacotherapy [18-20] have demonstrated improvements in several dimensions of HRQoL using various versions of the SF-36 and IWQOL. Physical functioning is the aspect of HRQoL that has consistently shown the most improvement across studies to-date [18]. In the Diabetes Prevention Program, a randomized controlled trial in over 3200 individuals with prediabetes (mean body mass index (BMI): $34 \mathrm{~kg} / \mathrm{m}^{2}$ ) comparing intensive lifestyle intervention, metformin and placebo, the mean change from baseline compared to placebo over 3.2 years in the SF-36 physical function domain was 3.58 in the lifestyle group versus 0.13 in the metformin group $(p<0.01)$ [21].

Pharmacotherapy weight-loss trials have recently reported changes in physical function using both the SF-36v2 and different versions of IWQOL. The glucagon-like peptide-1 receptor agonist (GLP-1RA), liraglutide, yielded a statistically significant improvement in physical function score compared to placebo at 3 years (3.65 vs 2.18 on the SF-36v2 and 13.47 vs 8.99 on the IWQOL)[22]. More recently, the longacting GLP-1RA, semaglutide has demonstrated statistically significant placebo-adjusted improvements of 1.5 to 1.8 on the SF-36v2 physical function score and 4.8 to 9.4 on the IWQOL-Lite-CT physical function score[23, 24].

Although these randomized controlled trials have shown statistically significant patient-reported improvement in physical function after weight-loss interventions, it is not clear if the magnitude of observed change is clinically meaningful within the populations studied. Some studies applied definitions of meaningful difference for SF-36 scores that were based on the general population or other disease states[21], rather than the population with overweight or obesity. For the IWQOL measures, meaningful change thresholds have been developed for individuals with overweight and obesity, but only for the IWQOL-Lite version[25], and not for the more recently used IWQOL-Lite CT version.

Without an established threshold for what constitutes a meaningful change, it is difficult to interpret the potential therapeutic benefit of weight-loss interventions with regards to physical functioning. The findings from a preliminary evidence review of published literature suggested that further qualitative research is required to establish patient-perceived meaningful change thresholds for the SF36v2 and the IWQOL-Lite-CT in individuals living with overweight or obesity.

Therefore, a qualitative interview study was conducted to explore participants' perceptions of meaningful weight-loss and to explore the level of change on the SF-36v2 (acute) and IWQOL-Lite-CT that individuals living with overweight or obesity consider to be meaningful and indicative of treatment success.

Participants' perception of meaningful improvement in physical function was also explored relative to 
percentage weight-loss in consideration of clinical guidelines that describe therapeutic efficacy according to thresholds of percent body weight [26-28].

\section{Methods}

The study protocol was approved by the New England Independent Review Board in September 2019. Ninety-minute, semi-structured interviews were conducted across three regions in the United States (West, South, and Midwest) with adults with overweight or obesity (BMI $\left.\geq 27 \mathrm{~kg} / \mathrm{m}^{2}\right)$. This BMI threshold was selected in order to include individuals who would meet criteria for pharmacologic weight-loss interventions, so the findings may be considered relevant to future pharmacologic weight-loss studies in which HRQoL is increasingly studied. Interviews included both concept elicitation and cognitive debriefing sections in which meaningful change was explored using a step-wise approach to aid participant understanding.

\section{Concept elicitation}

Concept elicitation is an open-ended form of qualitative interview, used to explore and define information from the perspective of individuals living with a condition [29]. Concept elicitation techniques can provide non-biased, spontaneous insights into what a meaningful change would be for individuals [30]. Concept elicitation explored the participants' perception of minimally important/meaningful weight-loss using open-ended questions, in a step-wise approach (Fig. 1) to allow participants to discuss the amount of body weight they would need to lose to have a noticeable improvement on their physical functioning.

\section{Cognitive debriefing}

Cognitive debriefing is a form of interviewing used to confirm comprehension and conceptual relevance of a clinical outcome assessment (COA) instrument in the population of interest. A "think aloud" technique is used, where participants are asked to speak their thought process aloud while completing the COA instrument [31]. Cognitive debriefing was used in the current study to establish participants' understanding, interpretation and relevance of the PRO measures.

\section{Meaningful change}

Cognitive debriefing was also used to understand thresholds for meaningful improvements or worsening on the response scales of each PRO measure. Example items with different response scales were taken from the SF-36v2 (acute) and IWQOL-Lite-CT. Participants were asked to consider the smallest change that would indicate a meaningful improvement and worsening on each scale. Participants were also asked to consider the anchors of a $5 \%, 10 \%$ and $15 \%$ weight-loss and how their answers would change based on each anchor.

A step-wise approach was utilized to explore meaningful change on each PRO. Interviewers began by establishing participant understanding of the response scale, ensuring correct interpretation of the 
response options and anchors. A visual aid was shown during the interview to help confirm participant understanding. This presented the item and response options with directional arrows to show improvement/worsening on each item. Once participant understanding was established, interviewers proceeded to explore improvement and worsening at the item-level.

Items from the physical function domain on each PRO were used to explore meaningful change with participants. The item selected to explore meaningful change thresholds on the SF-36v2 (acute) was "Item 3f: Bending, kneeling or stooping" as this was expected to be a highly relevant item across the sample based on prior literature. Response options were provided on a 3-point Likert scale (assessing severity of impacts) with responses ranging from 'Yes, limited a lot' to 'No, not limited at all'. For assessing meaningful improvement, participants were asked to consider 'yes, limited a lot' as their starting point and to select the smallest change from this point which would indicate a meaningful improvement in bending, kneeling or stooping. Participants were then asked to consider the anchors of $5 \%, 10 \%$ and $15 \%$ weight-loss and how they would expect their answers would change from 'yes, limited a lot,' or from 'No, not limited at all' for assessing meaningful worsening.

To explore the two different response scales used in the IWQOL-Lite-CT, "Item 2: I get tired or winded walking up one flight of stairs" and "Item 16: I am not as physically active as I would like to be" were selected. For Item 2, response options were provided on a 5-point Likert scale (assessing frequency of impacts) ranging from 'Never' to 'Always'. For assessing both meaningful improvement and worsening, participants were asked to consider 'sometimes' as the starting point and to select the smallest change from this point which would indicate a meaningful improvement or worsening in relation to becoming tired or winded walking up one flight of stairs. For Item 16, response options were provided on a 5-point Likert scale (assessing how true each statement is) ranging from 'Not at all true' to 'Completely true'. For both meaningful improvement and worsening, participants were asked to consider 'moderately true' as the starting point and to select the smallest change from this point which would indicate a meaningful improvement or worsening.

For both IWQOL-Lite-CT items, meaningful improvement was further assessed by asking participants to consider the anchors $5 \%, 10 \%$ and $15 \%$ weight-loss and how they expected their answers would change when considering each of the percentages.

\section{Results}

Thirty-three participants were interviewed (Table 1). The sample was equally split across male $(n=17$, $52 \%)$ and female $(n=16,48 \%)$ participants, with a mean age of 45 years old. Most participants were educated to high school diploma or equivalent $(n=14,42 \%)$, college/associate's degree $(n=7,21 \%)$ or Bachelor's degree $(n=7,21 \%)$. Geographical diversity within the US was also achieved across the South $(n=8,24 \%)$, Midwest $(n=12,36 \%)$, and West $(n=13,39 \%)$ 
The mean weight of the sample was $109 \mathrm{kgs}$ (range: $74-170 \mathrm{kgs}$ ). The mean BMI was $37.6 \mathrm{~kg} / \mathrm{m}^{2}$ (range: $27.4-56.6 \mathrm{~kg} / \mathrm{m}^{2}$ ). Of those participants who had weight-related comorbidities, fifteen reported only one $(n=15 / 24,63 \%)$ weight-related comorbidity. Comorbid conditions included T2DM $(n=12 / 24$, $50 \%)$, hypertension $(n=11 / 24,46 \%)$ and obstructive sleep apnea $(n=6 / 24,25 \%)$. The majority of the sample $(n=29 / 33,88 \%)$ were treatment naïve to weight-loss medications and surgery. Based on clinical characteristics, participants were classified into one of the following subgroups:

- Individuals with overweight or obesity $\left(B M I \geq 27 \mathrm{~kg} / \mathrm{m}^{2}\right)$ with T2DM

- Individuals with obesity (BMI $\geq 30 \mathrm{~kg} / \mathrm{m}^{2}$ ) without diabetes AND with one or more weight-related comorbidities (including: hypertension, dyslipidemia, obstructive sleep apnea or cardiovascular disease)

- Individuals with obesity $\left(\mathrm{BMI} \geq 30 \mathrm{~kg} / \mathrm{m}^{2}\right)$ without diabetes or any other weight-related comorbidities.

- Concept elicitation findings 
Table 1

Participant clinical characteristics and demographics

\begin{tabular}{|c|c|c|c|c|}
\hline $\begin{array}{l}\text { Clinical and } \\
\text { demographic } \\
\text { characteristics }\end{array}$ & $\begin{array}{l}\text { Total } \\
(\mathrm{N}= \\
33) \\
\mathrm{n}(\%)\end{array}$ & $\begin{array}{l}\text { Individuals with } \\
\text { overweight or } \\
\text { obesity }(\mathrm{BMI} \geq \\
\left.27 \mathrm{~kg} / \mathrm{m}^{2}\right) \text { with } \\
\text { T2DM } \\
(\mathrm{N}=12) \\
\mathrm{n}(\%)\end{array}$ & $\begin{array}{l}\text { Individuals with obesity } \\
\left.\text { (BMI } \geq 30 \mathrm{~kg} / \mathrm{m}^{2}\right) \text { without } \\
\text { diabetes, AND with } \geq 1 \\
\text { weight-related } \\
\text { comorbidity } \\
(\mathrm{N}=12) \\
\mathrm{n}(\%)\end{array}$ & $\begin{array}{l}\text { Individuals with } \\
\text { obesity (BMI } \geq 30 \\
\left.\mathrm{~kg} / \mathrm{m}^{2}\right) \text { without } \\
\text { diabetes or weight- } \\
\text { related comorbidities } \\
(\mathrm{N}=9) \\
\mathrm{n}(\%)\end{array}$ \\
\hline $\begin{array}{l}\text { Current weight } \\
\text { (kg) } \\
\text { Mean } \\
\text { (Median) } \\
\text { [Range] }\end{array}$ & $\begin{array}{l}109.2 \\
(104.3) \\
{[73.9-} \\
170.1]\end{array}$ & $\begin{array}{l}102.5(102.1) \\
{[73.9-148.8]}\end{array}$ & $\begin{array}{l}111(108.7) \\
{[88-140.2]}\end{array}$ & $\begin{array}{l}114.1(104.3) \\
{[84.4-170.1]}\end{array}$ \\
\hline $\begin{array}{l}\text { Current BMI } \\
\left(\mathrm{kg} / \mathrm{m}^{2}\right) \\
\text { Mean [Range] }\end{array}$ & $\begin{array}{l}37.6 \\
{[27.4-} \\
56.6]\end{array}$ & $\begin{array}{l}35.5 \\
{[27.4-49.9]}\end{array}$ & $\begin{array}{l}39.0 \\
{[30.0-56.6]}\end{array}$ & $\begin{array}{l}38.4 \\
{[30.0-50.9]}\end{array}$ \\
\hline $\begin{array}{l}\text { Comorbidities* } \\
\text { Type } 2 \\
\text { diabetes } \\
\text { Hypertension } \\
\text { Obstructive } \\
\text { sleep apnea } \\
\text { Dyslipidemia } \\
\text { Cardiovascular } \\
\text { disease }\end{array}$ & $\begin{array}{l}12 \\
(36 \%) \\
11 \\
(33 \%) \\
6 \\
(18 \%) \\
3(9 \%) \\
3(9 \%)\end{array}$ & $\begin{array}{l}12(100 \%) \\
3(25 \%) \\
1(8 \%) \\
1(8 \%) \\
2(17 \%)\end{array}$ & $\begin{array}{l}N / A^{ \pm} \\
8(67 \%) \\
5(42 \%) \\
2(17 \%) \\
1(8 \%)\end{array}$ & $\begin{array}{l}\text { N/A } \\
\text { N/A } \\
\text { N/A } \\
\text { N/A } \\
\text { N/A }\end{array}$ \\
\hline $\begin{array}{l}\text { Weight-loss } \\
\text { treatment } \\
\text { history }\end{array}$ & $\begin{array}{l}1(3 \%) \\
3(9 \%)\end{array}$ & 0 & $\begin{array}{l}1(8 \%) \\
1(8 \%)\end{array}$ & $\begin{array}{l}0 \\
2(22 \%)\end{array}$ \\
\hline $\begin{array}{l}\text { Currently on } \\
\text { treatment } \\
\text { Previously } \\
\text { received } \\
\text { treatment } \\
\text { Treatment } \\
\text { naive }\end{array}$ & $\begin{array}{l}29 \\
(88 \%)\end{array}$ & $12(100 \%)$ & 10 (83\%) & 7 (78\%) \\
\hline
\end{tabular}

Weight was reported by participants in pounds, but has been converted into kg

* Clinicians may have selected multiple responses for each participant; \pm Not applicable due to the sub-group eligibility criteria (e.g., Obesity without diabetes or weight-related comorbidities) 


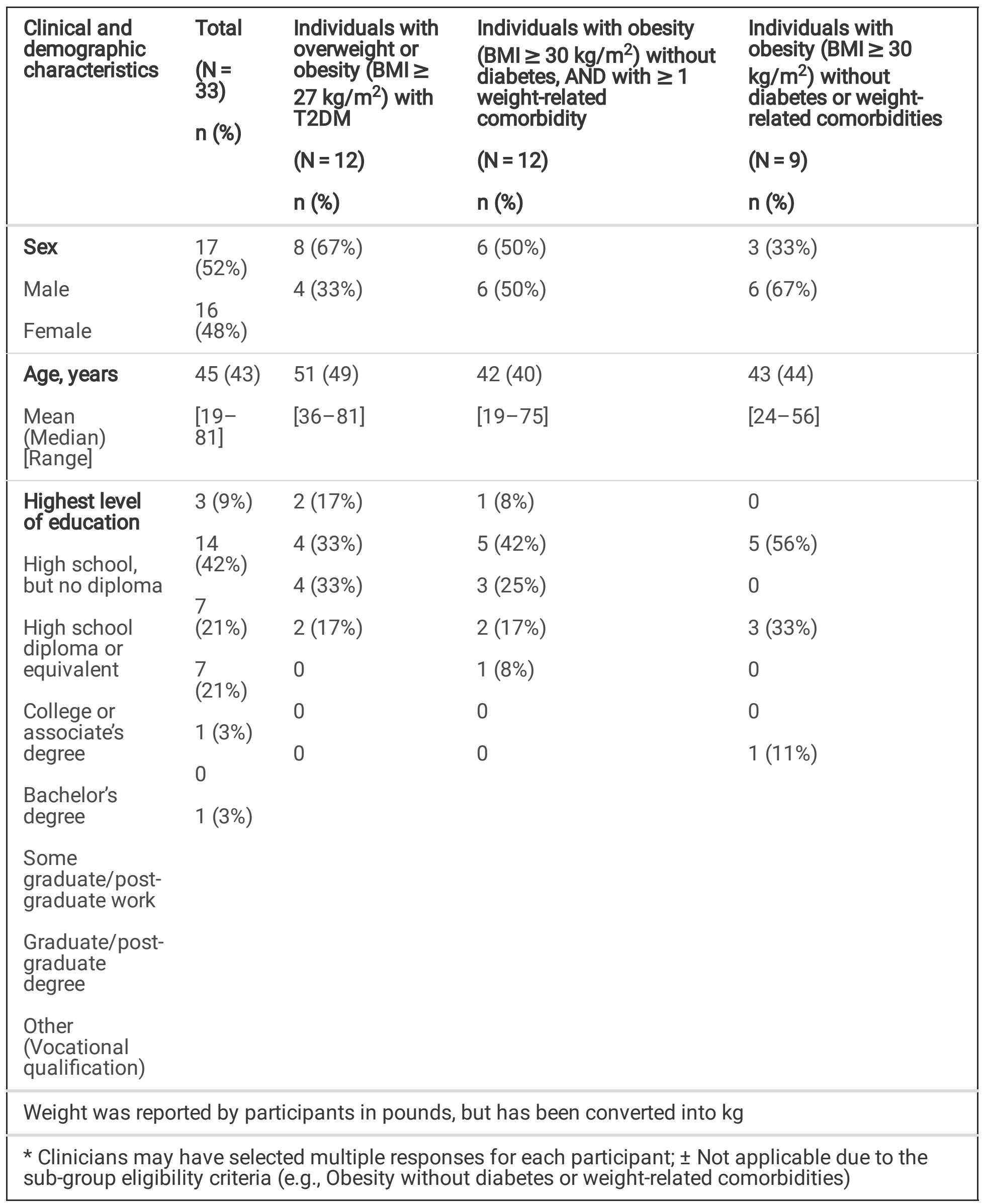


Participants were familiarized with the concept of minimally important weight-loss and discussing the amount of body weight they would expect to lose to have a noticeable improvement on their physical functioning in the concept elicitation portion of the interview.

\section{How participants assess weight-loss}

When asked to discuss weight-loss in their own words, most participants described measuring and thinking of weight-loss using a combination of terms including pounds $(n=28)$, clothing size $(n=16)$, inches $(n=2)$ and BMI $(n=2)$.

- I: So, first of all, in what units or terms do you typically talk about weight or measuring your weight? "The weight itself? I guess it would be in pounds." (Male, 36, BMI: $34.7 \mathrm{~kg} / \mathrm{m}^{2}$ )

- "I always think of it in terms of clothing sizes or pounds." (Female, 44, BMI: $47.3 \mathrm{~kg} / \mathrm{m}^{2}$ )

One participant in the sample described how they did not measure their weight-loss numerically, but based it on changes in physical appearance. Another participant described thinking of improvement in their ability to do physical activities when measuring weight-loss.

\section{Units used to discuss weight-loss}

The majority of participants spoke in pounds $(n=22)$, but a number of participants $(n=7)$ were able to offer answers in percentages. Two participants had difficulty with percentages and a further two participants did not answer. This suggested that participants were not familiar with independently thinking of weight-loss in terms of percentage. They found it challenging to visualize a percentage loss of their total body weight and the implications this would have on their ability to perform physical activities.

\section{Participant interpretations of percentage weight-loss}

As some participants appeared to have difficulty understanding the concept of a percentage weight-loss, interviewers provided the number of pounds the percentage weight-loss would equate to for that individual's weight. Participants spoke both in terms of improvement in their ability to perform physical activities and physical appearance and when asked, were able to explain what difference the weight-loss would make in their daily activities (Table 2 ).

Additionally, when discussing the smallest percentage change in body weight that would be noticeable and considered meaningful, fourteen participants spontaneously spoke about increased energy levels before thinking of how this would impact their physical functioning and specific daily activities.

\section{$5 \%$ total body weight-loss:}

Over two-thirds of participants $(23 / 33,70 \%)$ felt that a $5 \%$ weight-loss would be noticeable. When discussing the difference a $5 \%$ weight-loss would make, participants mentioned they would expect increased energy $(n=7)$ /stamina $(n=2)$, to be more active $(n=3)$ and feel 'lighter on their feet' $(n=1)$. When speaking of physical functioning, participants expected a noticeable difference/improvement in their ability to stand $(n=2)$, walk distances $(n=2)$, and bend $(n=1)$ and expected increased mobility $(n=$ 
1). Additionally, participants expected a $5 \%$ weight-loss to reduce the pain experienced while completing daily activities $(n=3)$ and improve breathing $(n=2)$. Ten participants $(10 / 33,30 \%)$ did not feel $5 \%$ weightloss would be significant enough to make a difference to performing daily activities.

\section{$10 \%$ total body weight-loss:}

All participants $(33 / 33,100 \%)$ reported that a $10 \%$ weight-loss would be noticeable. When discussing $10 \%$ weight-loss, participants mentioned they would expect increased energy $(n=15)$ /stamina $(n=1)$, to be more agile/mobile $(n=5)$, with two participants specifically expecting to be able to move faster in addition to generally being more physically active $(n=4)$. Participants also discussed that a $10 \%$ weightloss would improve their ability to walk, either for longer distances or at a quicker pace $(n=5)$, hike $(n=2)$, run $(n=1)$ and complete household chores $(n=2)$. One participant, who had previously used a walker, also mentioned they would expect to be able to move without assistance. Similar to a $5 \%$ weight-loss, participants expected a reduction in the pain experienced whilst completing daily activities $(n=3)$ and improved breathing $(n=2)$.

\section{$15 \%$ total body weight-loss:}

All participants $(33 / 33,100 \%)$ reported that a $15 \%$ weight-loss would be noticeable. Participants discussed expecting improvements in climbing the stairs $(n=2)$, exercising $(n=2)$ and a noticeable improvement in ability to bend $(n=1)$ and when discussing a $15 \%$ weight-loss. One participant also reported they would expect to be able to care for themselves and not need to rely on others for assistance when moving around. Compared to a $5 \%$ or $10 \%$ weight-loss, twice as many participants expected a reduction in the pain experienced while completing daily activities $(n=6)$ with a $15 \%$ weight-loss and the same number expected improved breathing $(n=2)$. 
Table 2

Participant perceptions of meaningful weight-loss

\begin{tabular}{|c|c|c|c|}
\hline \multirow[t]{2}{*}{$\begin{array}{l}\% \\
\text { weight- } \\
\text { loss }\end{array}$} & \multicolumn{2}{|c|}{$\begin{array}{l}\text { Noticeable? } \\
(\mathrm{N}=33)\end{array}$} & \multirow[t]{2}{*}{ Participant quotes } \\
\hline & $\mathbf{Y}$ & $\mathbf{N}$ & \\
\hline \multirow[t]{6}{*}{$5 \%$} & \multirow{6}{*}{$\begin{array}{l}n=23 \\
(70 \%)\end{array}$} & \multirow{6}{*}{$\begin{array}{l}\mathrm{n}= \\
10 \\
(30 \%)\end{array}$} & - Yes, noticeable: \\
\hline & & & $\begin{array}{l}\text { - "I think that with some activities that I might want to do, I might be } \\
\text { able to walk to the end of the block. I think that that would give me } \\
\text { back some of my mobility." (Female, } 44, \text { BMl: } 47.3 \mathrm{~kg} / \mathrm{m}^{2} \text { ) }\end{array}$ \\
\hline & & & $\begin{array}{l}\text { - "... Being able to bend over and do stuff a little bit better." (Male, 32, } \\
\text { BMI: } 50.9 \mathrm{~kg} / \mathrm{m}^{2} \text { ) }\end{array}$ \\
\hline & & & - No, not noticeable: \\
\hline & & & $\begin{array}{l}\text { - "No, I don't think so. It would be nice, but I don't think it's noticeable or } \\
\text { would make a difference." (Male, 43, BMl: } 40.2 \mathrm{~kg} / \mathrm{m} \text { ) }\end{array}$ \\
\hline & & & $\begin{array}{l}\text { - "I don't think that's enough for me to lose really to be noticeable." } \\
\text { (Male, } 61,34.2 \mathrm{~kg} / \mathrm{m} \text { ) }\end{array}$ \\
\hline \multirow[t]{4}{*}{$10 \%$} & \multirow{4}{*}{$\begin{array}{l}n=33 \\
(100 \%)\end{array}$} & $\mathrm{n}=0$ & - Yes, noticeable: \\
\hline & & \multirow[t]{3}{*}{$(0 \%)$} & $\begin{array}{l}\text { - "It would make a big difference. I think like I said, I would be more } \\
\text { agile. I would have more energy to do things. I wouldn't feel as tired. } \\
\text { More energy I think."(Female, 50, BMI: } 35.2 \mathrm{~kg} / \mathrm{m}^{2} \text { ) }\end{array}$ \\
\hline & & & $\begin{array}{l}\text { - "And also, the activities you do. I mean, you're more - you want to do } \\
\text { them. Like before, you fretted doing cutting the grass; now you look } \\
\text { forward to cutting the grass." (Male, } 53, \mathrm{BMl}: 42.8 \mathrm{~kg} / \mathrm{m}^{2} \text { ) }\end{array}$ \\
\hline & & & $\begin{array}{l}\text { - "I could probably wear some of the clothes that I have hiding in my } \\
\text { closet that I haven't worn in a while [...] And then definitely my energy } \\
\text { level would be that much higher, you know [...] I can probably do more } \\
\text { planking and more activities at the gym." (Female, } 39, \mathrm{BMl}: 40.0 \mathrm{~kg} / \mathrm{m} \text { ) }\end{array}$ \\
\hline
\end{tabular}

For a $5 \%$ body weight-loss, individuals 'without T2DM but with at least one other weight-related comorbidity' were more likely to consider the change noticeable $(n=10 / 12,83 \%)$ than those 'with T2DM' $(n=8 / 12,67 \%)$ or those 'without T2DM or any other weight-related comorbidities' $(n=5 / 8$, $62.5 \%$; Fig. 3). 


\begin{tabular}{|c|c|c|c|}
\hline \multirow[t]{2}{*}{$\begin{array}{l}\% \\
\text { weight- } \\
\text { loss }\end{array}$} & \multicolumn{2}{|c|}{$\begin{array}{l}\text { Noticeable? } \\
(\mathrm{N}=33)\end{array}$} & \multirow[t]{2}{*}{ Participant quotes } \\
\hline & $\mathbf{Y}$ & $\mathbf{N}$ & \\
\hline \multirow[t]{5}{*}{$15 \%$} & \multirow{5}{*}{$\begin{array}{l}n=33 \\
(100 \%)\end{array}$} & $\mathrm{n}=0$ & - Yes, noticeable: \\
\hline & & \multirow[t]{4}{*}{$(0 \%)$} & $\begin{array}{l}\text { - "Oh, just like I said before, the more weight I lose, the more flexibility I } \\
\text { have and the less pain on the knees and on the back." (Male, 54, BMl: } \\
27.5 \mathrm{~kg} / \mathrm{m}^{2} \text { ) }\end{array}$ \\
\hline & & & $\begin{array}{l}\text { - "Yeah. I would be able to go up some stairs without losing breath. I } \\
\text { wouldn't stop halfway up the stairs. I only have } 15 \text { stairs. My daughter's } \\
\text { at the top and I'm in the middle. I'm catching my breath. It would just be } \\
\text { a really big change. I would be able to do things that I can't } \\
\text { now."(Female, } 20, \mathrm{BMI}: 33.9 \mathrm{~kg} / \mathrm{m}^{2} \text { ) }\end{array}$ \\
\hline & & & $\begin{array}{l}\text { - "I'd probably be able to walk. l'd probably be able to bend, throw, do } \\
\text { whatever." (Female, } 45, \text { BMl: } 39.9 \mathrm{~kg} / \mathrm{m}^{2} \text { ) }\end{array}$ \\
\hline & & & $\begin{array}{l}\text { - "Probably be able to go out hiking and do more things, like to go } \\
\text { amusement park and ride a rollercoasters, because those rollercoasters } \\
\text { are not big people friendly." (Male, 32, BMI: } 50.9 \mathrm{~kg} / \mathrm{m}^{2} \text { ) }\end{array}$ \\
\hline \multicolumn{4}{|c|}{$\begin{array}{l}\text { For a } 5 \% \text { body weight-loss, individuals 'without T2DM but with at least one other weight-related } \\
\text { comorbidity' were more likely to consider the change noticeable }(n=10 / 12,83 \%) \text { than those 'with } \\
\text { T2DM' }(n=8 / 12,67 \%) \text { or those 'without T2DM or any other weight-related comorbidities' }(n=5 / 8 \text {, } \\
62.5 \% \text {; Fig. 3). }\end{array}$} \\
\hline
\end{tabular}

\section{Cognitive debriefing findings: SF-36v2 (acute)®}

Thirty-one participants were asked to complete the meaningful change task thinking about ltem $3 f$ (Bending, kneeling or stooping) of the SF-36v2 (acute) following the principles of the Scaffold Approach. Participants were asked to imagine they had selected 'Yes, limited a lot'.

A 1-point change at the item-level was considered the smallest meaningful improvement by the majority of participants $(n=28)$. A 1-point change at the item-level was also considered a meaningful improvement for most participants when considering how their ability to bend, kneel or stoop would change with a $5 \%(n=18)$ or $10 \%(n=16)$ total body weight-loss. However, participants expected a larger point change of 2-points with a $15 \%$ total body weight-loss $(n=21)$ (Table 3$)$. A 1-point change at the item-level was considered indicative of meaningful worsening for the majority of participants.

The findings were broadly consistent across the three overweight/obesity sub-groups (Table 4). When considering a $10 \%$ and a $15 \%$ weight-loss, the mean point score considered a meaningful change was higher for individuals 'without T2DM but at least one other weight-related comorbidity' (10\% mean: 1.7; 
15\% mean: 1.7) than those 'with T2DM' (10\% mean: $0.9 ; 15 \%$ mean: 1.5$)$ and those 'without T2DM or any other weight-related comorbidities' (10\% mean: $1.0 ; 15 \%$ mean: 1.6$)$.

\section{Cognitive debriefing findings: IWQOL-Lite-CT@}

\section{Frequency response scale}

Thirty-one participants were asked to complete the meaningful change task thinking about Item 2 (Tired or winded walking up one flight of stairs) of the IWQOL-Lite-CT, which utilized a frequency scale. Participants were asked to imagine they had selected 'sometimes'.

A 1-point change at the item-level was considered the smallest meaningful improvement by the majority of participants $(n=29)$. A 1-point change at the item-level was also considered a meaningful improvement for most participants when considering how their ability to walk up one flight of stairs without feeling tired or winded would change with a $5 \%(n=19)$ or $10 \%(n=16)$ total body weight-loss. However, participants expected a larger point change of 2-points with a $15 \%$ weight-loss $(n=20)$ (Table 3). A 1-point change at the item-level was considered indicative of meaningful worsening by the majority of participants.

The findings were broadly consistent across the three overweight/obesity sub-groups (Table 4). When considering a $10 \%$ and a $15 \%$ weight-loss, the mean point scores were higher for individuals 'without T2DM but at least one other weight-related comorbidity' (10\% mean: $1.5 ; 15 \%$ mean: 1.9 ) than those 'with T2DM' (10\% mean: $1.1 ; 15 \%$ mean: 1.5$)$ and those 'without T2DM or any other weight-related comorbidities' (10\% mean: 1.0; $15 \%$ mean: 1.3 ).

\section{'Truth' response scale}

Thirty-one participants were asked to complete the meaningful change task thinking about Item 16 (Not as physically active as I would like to be) of the IWQOL-Lite-CT, which utilized a truth scale. Participants were asked to imagine they had selected 'moderately true'.

A 1-point change at the item-level was considered the smallest meaningful improvement by the majority of participants $(n=27)$. A 1-point change at the item-level was also considered a meaningful improvement for most participants when considering how their ability to be physically active would change with a $5 \%(n=18)$ or $10 \%(n=17)$ total body weight-loss. However, participants expected a larger point change of 2-points with a $15 \%$ weight-loss $(n=19)$ (Table 3$)$. A 1-point change at the item-level was considered indicative of meaningful worsening for the majority of participants.

The findings were broadly consistent across the three overweight/obesity sub-groups (Table 4). When considering a $5 \%, 10 \%$ and a $15 \%$ weight-loss, the mean point scores were higher for individuals 'without T2DM but at least one other weight-related comorbidity' (5\% mean: $0.9,10 \%$ mean: $1.5 ; 15 \%$ mean: 2.0 ) than those 'with T2DM' (5\% mean: $0.4,10 \%$ mean: $1.0 ; 15 \%$ mean: 1.4$)$ and those 'without T2DM or any other weight-related comorbidities' ( $5 \%$ mean: $0.4,10 \%$ mean: $1.0 ; 15 \%$ mean: 1.5$)$. 
Perceptions of meaningful change on the SF-36v2 (acute) and the IWQOL-Lite-CT

SF-36v2 (acute) - Item $3 f$ - bending, kneeling or stooping (Severity scale)

Change from baseline 'Yes, limited Point change considered meaningful

Meant a lot'

$\begin{array}{lll}\mathbf{0} & \mathbf{+ 1} & \mathbf{+ 2} \\ \text { Yes, limited a } & \begin{array}{l}\text { Yes, limited a } \\ \text { lot }\end{array} & \begin{array}{l}\text { No, not limited } \\ \text { at all }\end{array}\end{array}$

Smallest meaningful improvement

$0 \quad 28$

3

1.1

$(\mathrm{n}=31)$

$5 \%$ weight-loss $(n=31)$

11

18

2

0.7

$10 \%$ weight-loss $(n=31)$

4

16

11

1.2

$15 \%$ weight-loss $(n=31)$

3

7

21

1.6

Change from baseline 'No, not limited at all'

Point change considered meaningful

Mean†

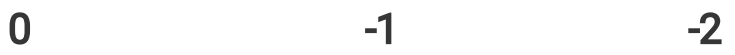

No, not limited Yes, limited a Yes, limited a at all little lot

Smallest meaningful worsening ( $\mathrm{n} \quad 0$ = 29)

19

10

1.3

IWQOL-Lite-CT Item 2 - Tired or winded walking up one flight of stairs (Frequency scale)

Change from baseline 'Sometimes' Point change considered meaningful

Meant

\begin{tabular}{|c|c|c|c|c|}
\hline & & & & \\
\hline & 0 & -1 & -2 & \\
\hline & Sometimes & Rarely & Never & \\
\hline $\begin{array}{l}\text { Smallest meaningful improvement } \\
(\mathrm{n}=31)\end{array}$ & 0 & 29 & 2 & 1.1 \\
\hline $5 \%$ weight-loss $(n=31)$ & 11 & 19 & 1 & 0.7 \\
\hline $10 \%$ weight-loss $(n=31)$ & 4 & 16 & 11 & 1.2 \\
\hline $15 \%$ weight-loss $(n=31)$ & 2 & 9 & 20 & 1.6 \\
\hline \multirow[t]{3}{*}{ Change from baseline 'Sometimes' } & \multicolumn{3}{|c|}{ Point change considered meaningful } & Meant \\
\hline & 0 & +1 & +2 & \\
\hline & Sometimes & Usually & Always & \\
\hline
\end{tabular}

† Mean rounded to one decimal place. Shaded cells indicate the most frequently selected point change. 
SF-36v2 (acute) - Item 3f - bending, kneeling or stooping (Severity scale)

Smallest meaningful worsening $(\mathrm{n} \quad \mathbf{0}$

26

4

1.1 $=30$ )

IWQOL-Lite-CT - Item 16 - Not as physically active as I would like to be (Truth scale)

Change from baseline 'Moderately Point change considered meaningful

Meant true'

$\begin{array}{lll}0 & -1 & -2 \\ \text { Moderately true } & \text { A little true } & \text { Not at all true }\end{array}$

\begin{tabular}{|c|c|c|c|c|}
\hline $\begin{array}{l}\text { Smallest meaningful improvement } \\
(\mathrm{n}=29)\end{array}$ & 0 & 27 & 2 & 1.1 \\
\hline $5 \%$ weight-loss $(n=30)$ & 12 & 18 & 0 & 0.6 \\
\hline $10 \%$ weight-loss $(n=31)$ & 4 & 17 & 10 & 1.2 \\
\hline $15 \%$ weight-loss $(n=30)$ & 0 & 11 & 19 & 1.6 \\
\hline \multirow{3}{*}{$\begin{array}{l}\text { Change from baseline 'Moderately } \\
\text { true' }\end{array}$} & \multicolumn{3}{|c|}{ Point change considered meaningful } & Meant \\
\hline & 0 & +1 & +2 & \\
\hline & Moderately true & Mostly true & Completely true & \\
\hline $\begin{array}{l}\text { Smallest meaningful worsening ( } \mathrm{n} \\
=29 \text { ) }\end{array}$ & 0 & 20 & 9 & 1.3 \\
\hline
\end{tabular}


Table 4

Perceptions of meaningful change on the SF-36v2 (acute) the IWQOL-Lite-CT among overweight/obesity subgroups

\section{SF-36v2 (acute) - Item $3 f$ - bending, kneeling or stooping (Severity scale)}

Change from baseline 'Yes, limited a lot'

\section{Mean point change considered} meaningful $\dagger$

\section{Smallest meaningful improvement $(n=31)$}

Individuals with overweight or obesity $\left(B M I \geq 27 \mathrm{~kg} / \mathrm{m}^{2}\right)$ with T2DM

Individuals with obesity $\left(B M I \geq 30 \mathrm{~kg} / \mathrm{m}^{2}\right)$ without T2DM but with other comorbidities

Individuals with obesity $\left(B M I \geq 30 \mathrm{~kg} / \mathrm{m}^{2}\right)$ without T2DM or any other comorbidities

\section{$5 \%$ weight-loss $(n=31)$}

Individuals with overweight or obesity $\left(B M I \geq 27 \mathrm{~kg} / \mathrm{m}^{2}\right)$ with

0.6 T2DM

Individuals with obesity $\left(B M I \geq 30 \mathrm{~kg} / \mathrm{m}^{2}\right)$ without T2DM but with other comorbidities

Individuals with obesity $\left(B M I \geq 30 \mathrm{~kg} / \mathrm{m}^{2}\right)$ without $T 2 D M$ or any

0.6 other comorbidities

\section{$10 \%$ weight-loss $(n=31)$}

Individuals with overweight or obesity $\left(B M I \geq 27 \mathrm{~kg} / \mathrm{m}^{2}\right)$ with T2DM

Individuals with obesity $\left(B M I \geq 30 \mathrm{~kg} / \mathrm{m}^{2}\right)$ without T2DM but with other comorbidities

Individuals with obesity $\left(B M I \geq 30 \mathrm{~kg} / \mathrm{m}^{2}\right)$ without T2DM or any other comorbidities

\section{$15 \%$ weight-loss $(n=31)$}

Individuals with overweight or obesity $\left(B M I \geq 27 \mathrm{~kg} / \mathrm{m}^{2}\right)$ with T2DM

Individuals with obesity $\left(B M I \geq 30 \mathrm{~kg} / \mathrm{m}^{2}\right)$ without T2DM but with other comorbidities

Individuals with obesity $\left(B M I \geq 30 \mathrm{~kg} / \mathrm{m}^{2}\right)$ without T2DM or any 1.6 other comorbidities

† Mean rounded to one decimal place. 
SF-36v2 (acute) - Item 3f - bending, kneeling or stooping (Severity scale)

Change from baseline 'No, not limited at all'

Mean point change considered meaningful $\dagger$

\section{Smallest meaningful worsening $(n=29)$}

Individuals with overweight or obesity $\left(B M I \geq 27 \mathrm{~kg} / \mathrm{m}^{2}\right)$ with

T2DM

Individuals with obesity $\left(B M I \geq 30 \mathrm{~kg} / \mathrm{m}^{2}\right)$ without T2DM but with other comorbidities

Individuals with obesity $\left(B M I \geq 30 \mathrm{~kg} / \mathrm{m}^{2}\right)$ without T2DM or any 1.4 other comorbidities

IWQOL-Lite-CT Item 2 - Tired or winded walking up one flight of stairs (Frequency scale) Change from baseline 'Sometimes' Mean point change considered meaningful $\boldsymbol{t}$

\section{Smallest meaningful improvement $(n=31)$}

Individuals with overweight or obesity $\left(B M I \geq 27 \mathrm{~kg} / \mathrm{m}^{2}\right)$ with

1.0

T2DM

Individuals with obesity $\left(B M I \geq 30 \mathrm{~kg} / \mathrm{m}^{2}\right)$ without T2DM but with other comorbidities

Individuals with obesity $\left(B M I \geq 30 \mathrm{~kg} / \mathrm{m}^{2}\right)$ without T2DM/or any other comorbidities

$5 \%$ weight-loss $(n=31)$

Individuals with overweight or obesity $(B M I \geq 27 \mathrm{~kg} / \mathrm{m2})$ with T2DM

Individuals with obesity (BMI $\geq 30 \mathrm{~kg} / \mathrm{m} 2)$ without T2DM but

with other comorbidities

Individuals with obesity (BMI $\geq 30 \mathrm{~kg} / \mathrm{m} 2)$ without / T2DM/or

0.7

any other comorbidities

$10 \%$ weight-loss $(n=31)$

Individuals with overweight or obesity $(B M I \geq 27 \mathrm{~kg} / \mathrm{m} 2)$ with T2DM

Individuals with obesity $(B M I \geq 30 \mathrm{~kg} / \mathrm{m} 2)$ without T2DM but with other comorbidities

Individuals with obesity (BMI $\geq 30 \mathrm{~kg} / \mathrm{m} 2)$ without T2DM/or any 1.0 other comorbidities

† Mean rounded to one decimal place. 
SF-36v2 (acute) - Item 3f - bending, kneeling or stooping (Severity scale)

$15 \%$ weight-loss $(n=31)$

Individuals with overweight or obesity $(B M I \geq 27 \mathrm{~kg} / \mathrm{m} 2)$ with T2DM

Individuals with obesity (BMI $\geq 30 \mathrm{~kg} / \mathrm{m} 2)$ without T2DM but with other comorbidities

Individuals with obesity $(B M I \geq 30 \mathrm{~kg} / \mathrm{m} 2)$ without T2DM or any 1.3 other comorbidities

Change from baseline 'No, not limited at all' Mean point change considered meaningful $\boldsymbol{t}$

\section{Smallest meaningful worsening $(n=30)$}

Individuals with overweight or obesity $(B M I \geq 27 \mathrm{~kg} / \mathrm{m} 2)$ with T2DM

Individuals with obesity (BMI $\geq 30 \mathrm{~kg} / \mathrm{m} 2)$ without T2DM but

with other comorbidities

Individuals with obesity (BMI $\geq 30 \mathrm{~kg} / \mathrm{m} 2)$ without T2DM or any

1.2

other comorbidities

IWQOL-Lite-CT - Item 16 - Not as physically active as I would like to be (Truth scale)

Change from baseline 'Moderately true'

Mean point change considered meaningful $\uparrow$

\section{Smallest meaningful improvement $(n=29)$}

Individuals with overweight or obesity $\left(B M I \geq 27 \mathrm{~kg} / \mathrm{m}^{2}\right)$ with

T2DM

Individuals with obesity $\left(B M I \geq 30 \mathrm{~kg} / \mathrm{m}^{2}\right)$ without T2DM but with other comorbidities

Individuals with obesity (BMI $\left.\geq 30 \mathrm{~kg} / \mathrm{m}^{2}\right)$ without T2DM or any

other comorbidities

$5 \%$ weight-loss $(n=30)$

Individuals with overweight or obesity $\left(B M I \geq 27 \mathrm{~kg} / \mathrm{m}^{2}\right)$ with

0.4

T2DM

Individuals with obesity $\left(B M I \geq 30 \mathrm{~kg} / \mathrm{m}^{2}\right)$ without T2DM but with

0.9

other comorbidities

Individuals with obesity (BMI $\left.\geq 30 \mathrm{~kg} / \mathrm{m}^{2}\right)$ without T2DM or any

0.4 other comorbidities

† Mean rounded to one decimal place. 


\section{SF-36v2 (acute) - Item 3f - bending, kneeling or stooping (Severity scale)}

\section{$10 \%$ weight-loss $(n=31)$}

Individuals with overweight or obesity $\left(B M I \geq 27 \mathrm{~kg} / \mathrm{m}^{2}\right)$ with T2DM

Individuals with obesity $\left(B M I \geq 30 \mathrm{~kg} / \mathrm{m}^{2}\right)$ without T2DM but with other comorbidities

Individuals with obesity (BMI $\left.\geq 30 \mathrm{~kg} / \mathrm{m}^{2}\right)$ without T2DM or any other comorbidities

\section{$15 \%$ weight-loss $(n=30)$}

Individuals with overweight or obesity $\left(B M I \geq 27 \mathrm{~kg} / \mathrm{m}^{2}\right)$ with T2DM

Individuals with obesity (BMI $\left.\geq 30 \mathrm{~kg} / \mathrm{m}^{2}\right)$ without T2DM but with other comorbidities

Individuals with obesity (BMI $\left.\geq 30 \mathrm{~kg} / \mathrm{m}^{2}\right)$ without T2DM or any other comorbidities

Change from baseline 'Moderately true'

\section{Smallest meaningful worsening $(n=29)$}

Individuals with overweight or obesity $\left(B M I \geq 27 \mathrm{~kg} / \mathrm{m}^{2}\right)$ with T2DM

Individuals with obesity $\left(B M I \geq 30 \mathrm{~kg} / \mathrm{m}^{2}\right)$ without T2DM but with other comorbidities

Individuals with obesity (BMI $\left.\geq 30 \mathrm{~kg} / \mathrm{m}^{2}\right)$ without T2DM or any other comorbidities
1.0

1.5

1.0

1.4

2.0

1.5

Mean point change considered meaningful $\dagger$

† Mean rounded to one decimal place.

\section{Discussion}

This study qualitatively explored perceptions of meaningful weight-loss for individuals living with overweight or obesity, and their perceptions of meaningful improvement in physical function as assessed by two PRO measures. Findings suggest nearly two-thirds of people living with overweight or obesity expect a $5 \%$ total body weight-loss to be enough to yield some benefit in physical functioning. Meanwhile, all participants expected a weight-loss of at least $10 \%$ to provide a meaningful and noticeable improvement to their physical functioning, such as participation in more strenuous or varied physical 
activities. This logical trend of increasing improvement to physical functioning due to an increased weight-loss is strong support that participants were able to understand the meaningful change tasks and provide examples of these improvements from their daily activities.

Previous research has highlighted a disparity between patients' expectations from weight-loss treatment and provider-directed weight-loss goals [32-34]. Individuals with overweight or obesity expect to reach an often unrealistic "goal weight" while providers aim for a more achievable 5-10\% initial weight-loss that yields metabolic benefits and cardiovascular risk reduction. The findings from this study suggest that potential improvement in physical function with $5-10 \%$ weight-loss is a clinical outcome that may be readily appreciated by patients, and as such, may be used by providers to help align patients on initial weight-loss goals $[26,28,27]$.

While the majority of participants in the current study reported that a 5-15\% weight-loss would be noticeable and provide a meaningful improvement to their physical functioning, there was a lack of understanding by many participants regarding how much of their total body weight the percentages would equate to until the interviewer converted this into absolute units (pounds). This suggests that individuals may not be able to conceptualize the idea of percentage reductions in body weight and therefore it may be more appropriate to discuss weight-loss with patients in terms of pounds or kilograms.

The data from cognitive debriefing provide an insight into the point-change that may represent a meaningful improvement or worsening at a single item-level on the SF-36v2 (acute) physical function domain and the IWQOL-Lite-CT from the participants' perspective. The majority of participants reported that a 1-point score change at the item-level would represent a meaningful improvement in their ability to carry out daily activities, and would be indicative of treatment success and a noticeable improvement in their physical functioning, such as being able to walk further or climb more flights of stairs. This itemlevel 1-point patient-perceived meaningful change threshold can help define the domain level minimal clinically important difference (MCID) in physical function resulting from weight-loss. Prior estimates of MCIDs for the IWQOL-Lite and SF-36 were based on quantitative anchor- and/or distribution-based methods, and did not incorporate qualitative patients' perspectives. Our qualitative findings can be combined with quantitative clinical trial data to inform a more clinically relevant MCID.

Overall, the findings from this study were broadly consistent across the pre-defined overweight/obesity sub-groups. In the cognitive debriefing meaningful change tasks, the sample of individuals 'without diabetes but at least one weight-related comorbidity' typically noted that they would expect to see a larger point-change with a $10 \%$ or $15 \%$ total body weight-loss than individuals 'with diabetes' and individuals 'without T2DM and any other weight-related comorbidities'. Additionally, this sub-group also noted during concept elicitation that a $5 \%$ weight-loss would be more noticeable when compared with the other two sub-groups. Therefore, expectations of weight-loss-induced physical and health benefits may vary according to subgroup. Weight-related comorbidities (e.g., hypertension, dyslipidemia, obstructive sleep 
apnea or cardiovascular disease) may lead to individuals expecting more substantial changes to their physical functioning following successful weight-loss.

This study does have some limitations that should be noted. The nature of qualitative research means that findings are based on a relatively small sample $(n=33)$ of individuals living with overweight/obesity in the United States. Although ethnic, racial and geographic diversity was achieved in the sample, results should still be generalized to a broader, cross-cultural population with caution. Each overweight/obesity sub-group in this study only included up to 12 participants, and therefore any differences among groups noted in this research should be considered exploratory and indicative rather than confirmatory. The PRO measures used in this study had relatively small response scales (3-point and 5-point Likert scales). To facilitate the cognitive debriefing meaningful change tasks, participants were asked to start at the midpoint of each response scale for the IWQOL-CT-Lite and at the higher or lower end of the response scale for SF-36v2, to allow comment on both improvement and worsening on the scale. As such, the results of this activity were somewhat limited by the number of possible responses.

The findings from this study provide an in-depth exploration of what individuals living with overweight and obesity consider to be a meaningful change in physical functioning; however this evidence should not be taken in isolation. This qualitative evidence should be triangulated with anchor and distribution based statistical analyses to establish values for minimally important differences on each PRO measure.

\section{Conclusion}

In summary, individuals living with overweight and obesity reported that they expect 5-15\% body weightlosses to be noticeable and provide meaningful improvements to their physical functioning, with $10 \%$ or higher weight-loss yielding the most consistent results. The findings from the cognitive debriefing tasks indicate that both SF-36v2 (acute) and IWQOL-CT-Lite PRO measures provide strong opportunity to demonstrate treatment benefit in relation to physical functioning and a 1 point change on the response scale would result in a noticeable improvement in participants' daily lives.

\section{Declarations}

\section{Funding}

Consultancy fees were paid by Eli Lilly and Company, the study sponsor, to Clarivate (formerly DRG Abacus) for running the study. Medical writing fees were also paid to Clarivate for preparation of the manuscript. There are no external funders to report for this submission.

\section{Conflicts of interest/competing interests}

Jiat-Ling Poon, Hongjun Kan, and Nadia N. Ahmad are employees and shareholders of Eli Lilly and Company. Chris Marshall, Chloe Johnson, Hannah C. Pegram are employees and stockholders of Clarivate, a health economic and outcomes research consultancy that consults with various 
pharmaceutical companies. Maile Hunter was an employee of Clarivate at the time this work was conducted.

\section{Availability of data and material}

Not applicable

\section{Code availability}

Not applicable

\section{Authors' contributions}

All authors contributed to the study concept, design and interpretation of findings. $\mathrm{CM}, \mathrm{CJ}, \mathrm{HP}$ and $\mathrm{MH}$ contributed to data collection and performed data analyses. All authors contributed to the review, critical revision and final approval of this manuscript.

\section{Ethics approval}

Ethics approval for the study was obtained from New England Independent Review Board (IRB\#: 120190277; September 2019).

\section{Informed consent}

All patients completed an informed consent form prior to interview and gave additional verbal consent at the time of the interview.

\section{Consent for publication}

All named authors have provided their consent for publication.

\section{Corresponding author}

Jiat-Ling Poon (jlpoon@lilly.com), Eli Lilly and Company, Indianapolis (IN), USA

\section{References}

1. Chooi YC, Ding C, Magkos F. The epidemiology of obesity. Metabolism - Clinical and Experimental. 2019;92:6-10. doi:10.1016/j.metabol.2018.09.005.

2. Institute for Health Metrics and Evaluation (IHME). Global Burden of Disease Study 2015 - Risk Factor Results 1990-2015. 2015. http://ghdx.healthdata.org/record/ihme-data/gbd-2015-risk-factorresults-1990-2015.

3. World Health Organization (WHO). Obesity and overweight: Key facts. 2020. https://www.who.int/en/news-room/fact-sheets/detail/obesity-and-overweight. 
4. Bhaskaran K, Douglas I, Forbes H, dos-Santos-Silva I, Leon DA, Smeeth L. Body-mass index and risk of 22 specific cancers: a population-based cohort study of 5.24 million UK adults. Lancet (London, England). 2014;384(9945):755-65. doi:10.1016/S0140-6736(14)60892-8.

5. Khaodhiar L, McCowen K, Blackburn G. Obesity and its comorbid conditions. . Clinical cornerstone. 1999;2(3):17-31.

6. Stefan N, Birkenfeld AL, Schulze MB. Global pandemics interconnected-obesity, impaired metabolic health and COVID-19. Nature Reviews Endocrinology. 2021:1-15.

7. Han TS, Tajar A, O'Neill TW, Jiang M, Bartfai G, Boonen S et al. Impaired quality of life and sexual function in overweight and obese men: the European Male Ageing Study. 2011;164(6):1003. doi:10.1530/eje-10-1129.

8. Ul-Haq Z, Mackay DF, Fenwick E, Pell JP. Meta-analysis of the association between body mass index and health-related quality of life among adults, assessed by the SF-36. Obesity. 2013;21(3):E322-E7. doi:10.1002/oby.20107.

9. da Silva SSP, da Costa Maia Â. Obesity and Treatment Meanings in Bariatric Surgery Candidates: A Qualitative Study. Obesity Surgery. 2012;22(11):1714-22. doi:10.1007/s11695-012-0716-y.

10. Cook NS, Tripathi P, Weiss O, Walda S, George AT, Bushell A. Patient needs, perceptions, and attitudinal drivers associated with obesity: a qualitative online bulletin board study. Advances in therapy. 2019;36(4):842-57.

11. Stone AA, Broderick JE. Obesity and pain are associated in the United States. Obesity. 2012;20(7):1491-5.

12. Kolotkin R, Meter K, Williams G. Quality of life and obesity. Obesity reviews. 2001;2(4):219-29.

13. Le Pen C, Lévy E, Loos F, Banzet MN, Basdevant A. "Specific" scale compared with "generic" scale: a double measurement of the quality of life in a French community sample of obese subjects. $J$ Epidemiol Community Health. 1998;52(7):445-50. doi:10.1136/jech.52.7.445.

14. Corica F, Corsonello A, Apolone G, Lucchetti M, Melchionda N, Marchesini G et al. Construct Validity of the Short Form-36 Health Survey and Its Relationship with BMI in Obese Outpatients. Obesity. 2006;14(8):1429-37. doi:10.1038/oby.2006.162.

15. Karlsen T-I, Tveitå EK, Natvig GK, Tonstad S, Hjelmesæth J. Validity of the SF-36 in patients with morbid obesity. Obesity Facts. 2011;4(5):346-51. doi:10.1159/000333406.

16. Kolotkin RL, Ervin CM, Meincke HH, Højbjerre L, Fehnel SE. Development of a clinical trials version of the Impact of Weight on Quality of Life-Lite questionnaire (IWQOL-Lite Clinical Trials Version): results from two qualitative studies. Clinical Obesity. 2017;7(5):290-9. doi:10.1111/cob.12197.

17. Kolotkin RL, Williams VSL, Ervin CM, Williams N, Meincke HH, Qin S et al. Validation of a new measure of quality of life in obesity trials: Impact of Weight on Quality of Life-Lite Clinical Trials Version. Clinical Obesity. 2019;9(3):e12310. doi:10.1111/cob.12310.

18. Kolotkin RL, Andersen JR. A systematic review of reviews: exploring the relationship between obesity, weight loss and health-related quality of life. Clinical obesity. 2017;7(5):273-89. 
19. Grams J, Garvey WT. Weight loss and the prevention and treatment of type 2 diabetes using lifestyle therapy, pharmacotherapy, and bariatric surgery: mechanisms of action. Current obesity reports. 2015;4(2):287-302.

20. Warkentin LM, Majumdar SR, Johnson JA, Agborsangaya CB, Rueda-Clausen CF, Sharma AM et al. Weight loss required by the severely obese to achieve clinically important differences in healthrelated quality of life: two-year prospective cohort study. BMC Med. 2014;12:175-. doi:10.1186/s12916-014-0175-5.

21. Florez H, Pan Q, Ackermann RT, Marrero DG, Barrett-Connor E, Delahanty L et al. Impact of lifestyle intervention and metformin on health-related quality of life: the diabetes prevention program randomized trial. Journal of general internal medicine. 2012;27(12):1594-601.

22. Kolotkin RL, Smolarz BG, Meincke H, Fujioka K. Improvements in health-related quality of life over 3 years with liraglutide $3.0 \mathrm{mg}$ compared with placebo in participants with overweight or obesity. Clinical obesity. 2018;8(1):1-10.

23. Wilding JP, Batterham RL, Calanna S, Davies M, Van Gaal LF, Lingvay I et al. Once-weekly semaglutide in adults with overweight or obesity. New England Journal of Medicine. 2021.

24. Davies M, Færch L, Jeppesen OK, Pakseresht A, Pedersen SD, Perreault L et al. Semaglutide 2. $4 \mathrm{mg}$ once a week in adults with overweight or obesity, and type 2 diabetes (STEP 2): a randomised, double-blind, double-dummy, placebo-controlled, phase 3 trial. The Lancet. 2021.

25. Crosby RD, Kolotkin RL, Williams GR. An integrated method to determine meaningful changes in health-related quality of life. Journal of clinical epidemiology. 2004;57(11):1153-60.

26. NHLBI. The National Heart Lung and Blood Institute (NHLBI) Practical Guide. 2000. https://www.nhlbi.nih.gov/files/docs/guidelines/prctgd_c.pdf.

27. Jensen MD, Ryan DH, Apovian CM, Ard JD, Comuzzie AG, Donato KA et al. 2013 AHA/ACC/TOS Guideline for the Management of Overweight and Obesity in Adults: A Report of the American College of Cardiology/American Heart Association Task Force on Practice Guidelines and The Obesity Society. Journal of the American College of Cardiology. 2014;63(25, Part B):2985-3023. doi:https://doi.org/10.1016/j.jacc.2013.11.004.

28. Garvey WT, Mechanick JI, Brett EM, Garber AJ, Hurley DL, Jastreboff AM et al. AMERICAN ASSOCIATION OF CLINICAL ENDOCRINOLOGISTS AND AMERICAN COLLEGE OF ENDOCRINOLOGY COMPREHENSIVE CLINICAL PRACTICE GUIDELINES FOR MEDICAL CARE OF PATIENTS WITH OBESITY. Endocrine practice : official journal of the American College of Endocrinology and the American Association of Clinical Endocrinologists. 2016;22 Suppl 3:1-203. doi:10.4158/ep161365.gl.

29. Patrick DL, Burke LB, Gwaltney CJ, Leidy NK, Martin ML, Molsen E et al. Content validity-establishing and reporting the evidence in newly developed patient-reported outcomes (PRO) instruments for medical product evaluation: ISPOR PRO Good Research Practices Task Force report: part 2-assessing respondent understanding. Value Health. 2011;14(8):978-88. doi:10.1016/j.jval.2011.06.013. 
30. Staunton H, Willgoss T, Nelsen L, Burbridge C, Sully K, Rofail D et al. An overview of using qualitative techniques to explore and define estimates of clinically important change on clinical outcome assessments. Journal of patient-reported outcomes. 2019;3(1):1-10.

31. Brédart A, Marrel A, Abetz-Webb L, Lasch K, Acquadro C. Interviewing to develop Patient-Reported Outcome (PRO) measures for clinical research: eliciting patients' experience. Health and quality of life outcomes. 2014;12(1):15.

32. Foster GD, Wadden TA, Vogt RA, Brewer G. What is a reasonable weight loss? Patients' expectations and evaluations of obesity treatment outcomes. Journal of consulting and clinical psychology. 1997;65(1):79.

33. DeJesus R, Bauer K, Bradley D, Haller I, Bradley S, Schroeder D et al. Experience and expectations of patients on weight loss: The Learning Health System Network Experience. Obesity science \& practice. 2019;5(5):479-86.

34. Fabricatore A, Wadden T, Womble L, Sarwer D, Berkowitz R, Foster G et al. The role of patients' expectations and goals in the behavioral and pharmacological treatment of obesity. International journal of obesity. 2007;31(11):1739-45.

\section{Figures}

\section{Familiarization with \\ concept of minimally \\ important weight-loss}

- Minimally important weight-loss was contextualized as the amount of body weight participants would expect to lose to have a noticeable improvement on their physical functioning

- Questioning was open-ended to allow participants to discuss weight-loss in their preferred terminology (e.g., pounds or clothing sizes)

\section{Introduction to thinking about weight loss as} percentages

- Participants were asked to think about the smallest percentage of weight they would need to lose to notice an improvement in carrying out physical activities

- If participants were unsure how many pounds a percentage of their total body weight would equate to, the interviewer converted the percentage to pounds
Consider specific

percentage-values of

weight loss

- Participants were asked to consider a $5 \%, 10 \%$ and $15 \%$ weight-loss in relation to their total body weight

- Participants were also asked the impact they would expect this weight-loss to have on their physical functioning

\section{Figure 1}

Concept elicitation to explore meaningful change 